\section{As práticas corporais na legislação imperial \\ e a construção de uma sociologia da profissão para a educação física}

\section{Bodily practices in imperial legislation and constructing a professional sociology for physical education}

\author{
Rubiane Giovani Fonseca ${ }^{i}$ \\ ' Docente, Departamento de Educação Física/ \\ Universidade Federal do Rio Grande do Norte. \\ Natal - RN - Brasil \\ orcid.org/0000-0003-0565-9165 \\ rubiane.fonseca@ufrn.br \\ Tony Honorato ${ }^{i i}$ \\ i Docente, Departamento de Educação/ \\ Universidade Estadual de Londrina. \\ Londrina - PR - Brasil \\ orcid.org/0000-0003-3057-1157 \\ tony@uel.br
}

\section{Samuel de Souza Neto ${ }^{i i}$}

iii Docente, Departamento de Educação/ Universidade Estadual Paulista Júlio de Mesquita Filho. Rio Claro - SP - Brasil

orcid.org/0000-0002-8991-7039

samuelsn@rc.unesp.br

Recebido em 23 mar. 2019.

Aprovado em 24 set. 2019.
FONSECA, Rubiane Giovani; HONORATO, Tony; SOUZA NETO, Samuel de. As práticas corporais na legislação imperial e a construção de uma sociologia da profissão para a educação física. História, Ciências, Saúde - Manguinhos, Rio de Janeiro, v.28, n.2, abr.-jun. 2021, p.509-526.

\section{Resumo}

O artigo aborda os ofícios ligados à educação física, perante leis e decretos oficiais do período imperial (1822-1889), tendo em vista traçar uma trajetória dos primeiros passos articulados pelos profissionais nos contextos civil e militar da sociedade brasileira antes de eles serem reconhecidos como membros de uma categoria profissional. Optou-se por um estudo documental de leis e decretos imperiais que mencionam os ofícios vinculados às práticas corporais. Nesse contexto foi identificado que, ao contrário dos trabalhos intelectuais, a baixa atratividade dos trabalhos práticos dificultava a dedicação exclusiva, assim como a estabilidade no exercício do trabalho. Esses elementos eram obstáculos para reivindicações mais organizadas da educação física, necessárias para sua profissionalização.

Palavras-chave: legislação; instituições sociais; profissionalização; sociologia das profissões; educação física.

\section{Abstract}

This documentary study examines official texts related to physical education in legislation and decrees from Brazil's imperial period (1822-1889) to trace the initial steps of professionals in this area within the civil and military context of Brazilian society, before they were recognized as a professional category. We found that unlike intellectual efforts, practical work was less attractive, which made it difficult for these professionals to work exclusively and maintain stability in this area. These elements were obstacles to more organized demands from physical education that were required for professionalization.

Keywords: legislation; social institutions; professionalization; sociology of professions; physical education. 
$\mathrm{O}$ presente artigo evidencia elementos da organização e valorização ocupacional da educação física no Brasil durante o período imperial (1822-1889), dando atenção, especificamente, às relações que os sujeitos envolvidos com o ensino das práticas corporais estabeleciam com o poder oficial e com a própria sociedade. No âmbito desse cenário, que exige retratar uma realidade num tempo e espaço, não temos como objetivo realizar uma análise histórica, mas sim sociológica, sobre a estrutura ocupacional dos ofícios vinculados às práticas corporais no período imperial, a partir da análise documental.

Em tempos imperiais, educação física era entendida como uma prática corporal com o intuito civilizatório passando por questões mais amplas como higiene, saúde, passatempo, formação de militares do Exército nacional, culturas imigratórias, formas de educar o corpo, em termos objetivos (vestuário, alimentação, cuidados físicos) e subjetivos (sentimentos, valores), e não estrita a uma disciplina do currículo escolar. Como uma prática corporal, a educação física compunha os debates sobre a identidade nacional, projetos de nação e a forja de uma elite nacional no período oitocentista (Melo, Peres, 2014; Melo, 2018). Para Melo $(2016,2018)$, as atividades de dança, esgrima, ginástica, natação, equitação e jogos representam os primeiros indícios da formação de um mercado de ensino das práticas corporais, compondo uma noção de educação física em espaços escolares e não escolares no século XIX.

Assim, empreende-se neste artigo uma análise sobre a incipiente profissionalização, mais especificamente, sobre a sociogênese da institucionalização da educação física como uma profissão que se erigia aos poucos na pretendida modernização do Brasil após a independência do período colonial. Ao longo deste texto, apresentaremos a forma como os mestres, que atuavam com as práticas corporais comuns a época, eram nomeados e remunerados, como eram delimitadas as suas atribuições ocupacionais nos diferentes contextos sociais e, mesmo que de forma incipiente, sinalizaremos a edificação de uma sociologia da profissão educação física.

Destaca-se, ainda, que o cenário ocupacional no Brasil do século XIX correspondia aos ofícios que, de alguma forma, atuavam em prol das necessidades do poder oficial e das elites imperiais que advogavam pela emergência e expansão de regular o comércio, os modos culturais, a vida educativa, a promoção de higiene e saúde, a garantia de segurança nacional e as necessidades de infraestrutura das cidades em crescimento (Schwarcz, 1998; Gondra, 2008). Entre as escolhas clássicas desse período é possível mencionar a medicina, o direito e a engenharia (Coelho, 1999). Entretanto, com o crescimento das cidades, uma série de questões sociais como a criminalidade, a saúde, a educação passou a demandar novas soluções e serviços, cada vez mais especializados, de novos grupos profissionais. Os ofícios ligados às práticas corporais surgem como uma derivação das novas demandas da sociedade imperial.

Médicos, cirurgiões, militares, engenheiros, advogados, entre outros que provavam seus dotes e habilidades atléticas, aos poucos foram defendendo, difundindo e garantindo a presença das práticas corporais na sociedade brasileira. Tal percurso permite considerar que, na constituição do projeto profissional, "a educação física brasileira foi inventada pela prática de agentes leigos e apropriada pelo discurso de agentes de diversas profissões interessadas em instituí-la como cultura de modernização nacional" (Andrade Filho, 2001, p.1). 
Entretanto, até este momento, temos poucas informações sobre como os sujeitos que atuavam com as práticas corporais eram vistos pela sociedade e, mais especificamente, quais ações impactaram para desencadear o processo de profissionalização da ocupação que, no futuro, seria chamada de educação física.

Dessa forma, alguns questionamentos são necessários para melhor compreender a profissionalização da educação física brasileira: quais eram os campos de atuação e como o trabalho com as práticas corporais era caracterizado pela legislação imperial? Qual o grau de reconhecimento atribuído aos ofícios nas instituições em que as práticas corporais eram ministradas? Tais organizações poderiam ser comparadas a um processo rudimentar de profissionalização da educação física?

Para um entendimento do cenário ocupacional no período imperial, o próximo tópico apresentará as bases conceituais da sociologia das profissões para a compreensão da constituição ocupacional da educação física.

\section{A profissionalização da educação física na perspectiva da sociologia das profissões}

A sociologia das profissões apresenta-se como um manual de estudo sobre as ocupações que pode situar ou estabelecer um plano de observação e análise dos mais variados grupos ocupacionais (Rodrigues, 2002, p.1). A palavra "profissão" possui uma longa história em todas as línguas europeias originadas no latim. Derivada do vocábulo latino professio, significa originalmente declaração pública ou confissão (Coelho, 1999, p.20), ou ainda expressão de intenção ou propósito (Bosi, 1996, p.37). Portanto, ser um profissional representa fazer parte de um grupo reconhecido por ser comprometido com seu ofício e com os membros da própria comunidade.

Ao longo do tempo, com a complexidade das atividades laborais, as ocupações foram se apropriando de uma educação especializada e repleta de mistérios aos que não pertenciam aos círculos "profissionais". A educação profissional estava centrada nas experiências de um mestre de ofícios considerado expert, o qual transmitia seus conhecimentos apenas ao seu aprendiz e aos pares que compartilhavam o mesmo ofício. Tal educação profissional não se restringia apenas aos saberes do exercício laboral, mas contemplava um código de conduta e de fidelidade aos segredos aprendidos na convivência com o mestre, que era exclusivo do aprendiz (Rugiu, 1998).

Com o tempo, a educação profissional foi se transformando em algo cada vez mais complexo, contribuindo para o desenvolvimento dos conhecimentos científicos e os processos de trabalho formalizados e sistematizados, de forma que serviriam de referência para classificar e diferenciar aqueles que se aventurassem em uma carreira especializada daqueles que não tivessem a mesma instrução. Por esse motivo, os grupos profissionais modernos vão se esforçar para se diferenciar de outros grupos e dos leigos, por meio do uso de termos especializados, ferramentas e tecnologias que exigem treinamento prolongado e a avaliação das habilidades e competências profissionais pelos pares (Bosi, 1996).

Sendo assim, para o funcionamento do projeto profissional - transição do status de ofício para o de profissão - torna-se necessário que realmente haja a diferenciação entre o profissional e o não profissional pela formação especializada, para que os especialistas 
possam gozar de privilégios e da autoridade que os leigos não usufruem (Brante, 2011). A comunidade sanciona, por meio de seus legisladores, a autoridade das profissões e assegura aos profissionais certos poderes (Rosas, 1980), os quais, em contrapartida, não podem ser exercidos sem o apoio da comunidade ou do Estado.

As características das ocupações em fase de estruturação, como eram os ofícios ligados ao tratamento das doenças - boticários, parteiras, cirurgiões (Ribeiro, 1997) - ou aqueles das práticas corporais - mestres, professores, militares - do Brasil oitocentista (Coelho, 1999), fundamentavam-se na organização de um projeto profissional, mesmo que de forma rudimentar e pouco articulada, em relação às profissões da sociedade imperial já estabelecidas, como medicina, direito e engenharia. Ações de ordem corporativa tomavam força, tais como: (a) popularização das responsabilidades dos profissionais de cada ofício; (b) definição de critérios e escolas para a formação; (c) definição de protocolos e linguagens específicas; (d) código de ética para mediar as relações entre os profissionais e o público (Rosas, 1980).

Deve-se ter em mente que, apesar de uma organização embrionária das práticas corporais, atributos como o conhecimento especializado, o trabalho como um serviço para a comunidade, remuneração, códigos de conduta ou de identificação interna, podem ter sido fortemente articulados em prol de um projeto profissional idealizado para a legitimação do papel e dos privilégios sociais gozados pelas profissões tradicionais ou já estabelecidas. As profissões estabelecidas exercem poder de legitimar os novos exercícios profissionais. A respeito disso, como registra o estudo de Melo e Peres (2014), tem-se o caso de Guilherme Luiz de Taube, sueco naturalizado brasileiro que atuara nas Forças Armadas, que, quase uma década antes de atuar no Colégio Pedro II no ensino de ginástica, ${ }^{1}$ entregou, em 1832, à Sociedade de Medicina do Rio de Janeiro um documento de sua autoria que discutia os benefícios da ginástica, objetivando uma aprovação dos facultativos associados, com a expectativa de receber reconhecimento de sua iniciativa de trabalho com o ensino de ginástica.

\section{Orientações metodológicas}

Para descrever o cenário germinal da constituição ocupacional da educação física e ressaltar as primeiras menções aos ofícios ligados às práticas corporais, oficializados e regulados pelo poder imperial, optou-se pela pesquisa qualitativa e documental com base em fontes oficiais (leis e decretos imperiais). Contou-se também com fontes complementares como artigos, livros e outros meios, que serviram como ponto de partida para pensar as evidências e as relações estabelecidas com os contextos do tempo sócio-histórico retratado (Struna, 2002).

Os dados escolhidos foram os documentos oficiais que descrevem, caracterizam ou regulam o trabalho com as práticas corporais. Na análise de Phillips (1974), são considerados documentos quaisquer materiais escritos que possam ser usados como fonte de informação sobre o comportamento humano, tais como leis e regulamentos, normas, pareceres, cartas, memorandos, discursos, jornais, revistas, arquivos escolares, entre outros.

Utilizou-se para o levantamento dos dados o banco de legislações históricas, disponibilizado no site da Câmara dos Deputados. Para classificar as leis e os decretos 
relacionados às práticas corporais, utilizaram-se os seguintes descritores, escritos na forma adotada no período imperial: "gymnastica"; "saúde physica"; "educação physica"; "sport". Os documentos selecionados foram arquivados, organizados por ano e descritor.

A organização dos dados seguiu o exemplo do Quadro 1, contemplando as seguintes categorias: decreto e natureza das instituições mencionadas; atividades; população-alvo; fins das atividades para cada instituição; responsáveis e remuneração; a quem estava subordinada.

Quadro 1: Distribuição dos dados após leitura e marcação dos termos nos documentos

\begin{tabular}{|l|l|l|l|l|l|}
\hline $\begin{array}{l}\text { Orientação } \\
\text { (normativos) }\end{array}$ & $\begin{array}{l}\text { Atividade/ } \\
\text { Modalidade }\end{array}$ & $\begin{array}{l}\text { População- } \\
\text { alvo }\end{array}$ & Ofício/Salário & $\begin{array}{l}\text { A quem está } \\
\text { subordinada }\end{array}$ & Fonte de referência \\
\hline $\begin{array}{l}\text { Decreto } \\
\text { n.2.582, } \\
\text { de } 21 \text { de abril } \\
\text { de } 1860\end{array}$ & $\begin{array}{l}\text { Equitação } \\
\text { Natação } \\
\text { Ginástica }\end{array}$ & $\begin{array}{l}\text { Alunos saídos } \\
\text { das escolas } \\
\text { militares }\end{array}$ & $\begin{array}{l}\text { Mestres } \\
720 \$ 000 \\
+720 \$ 000=\end{array}$ & $\begin{array}{l}\text { Comandante- } \\
1.440 \$ 000\end{array}$ & $\begin{array}{l}\text { "Art. 68... haverá também 'mestres } \\
\text { de equitação, natação, ginástica } \\
\text { e hipiátrica, instrutores das três } \\
\text { armas', devendo os de primeira } \\
\text { escola central } \\
\text { classe ter o curso completo da } \\
\text { respectiva arma" (Destaque dos } \\
\text { autores) }\end{array}$ \\
\hline
\end{tabular}

* Estudo e desenvolvimento de práticas de cuidados com animais, prática esta que origina a medicina veterinária (Germiniani, 1998). Desse modo, o mestre de hipiátrica está relacionado ao foro veterinário no período retratado neste estudo.

Fonte: Elaborado pelos autores.

Foram identificados 48 decretos, uma carta e uma lei. ${ }^{2}$ Esses documentos contemplam desde a chegada da família imperial ao Brasil até o final do Império, em 1889. A partir da primeira seleção e classificação dos dados, foi possível reorganizá-los e agrupá-los em três segmentos de atuação dos mestres das práticas corporais identificadas nos documentos: nas "escolas civis", nas "escolas militares" e o terceiro nas "sociedades ginásticas".

Reconhece-se que, ao operar com as fontes eleitas, foi possível dialogar com algumas facetas do passado, sem a intencionalidade de versar sobre a totalidade das questões inerentes à sociedade imperial no Brasil. Isso porque, nos termos de Faria Filho (1998), os dispositivos legais não devem ser tratados mecanicamente como reveladores da realidade completa, deve-se reconhecê-los como práticas sociais produzidas por sujeitos envolvidos em lutas políticas, sociais, culturais e econômicas. Sendo assim, quando utilizamos as fontes oficiais, registramos as marcas que se institucionalizaram e repercutiram na configuração, também oficial, das responsabilidades que as ocupações foram assumindo em seu processo de formação.

Dessa forma, foi considerado pertinente pesquisar uma documentação marcada pelas preocupações oficiais sobre as práticas corporais daquele tempo, mesmo que nem sempre todas as prescrições tenham sido efetivamente praticadas. Além disso, é relevante demarcar que o propósito deste estudo concentra-se no processo de profissionalização de uma ocupação ainda em fase formativa, tal como as instituições que lhe atribuiriam legitimidade, pois, como Coelho $(1999$, p.61) pondera, se havia algum "Estado" no Brasil do Império, era um "Estado externo", sem raízes na sociedade. 


\section{Práticas corporais nas instituições escolares, escolas militares e sociedades ginásticas}

Na literatura produzida sobre a história da educação física brasileira (Castellani Filho, 1988; Soares, 1994, 2005; Ferreira Neto, 1999; Schneider, 2010; Herold Júnior, 2007; Melo, $2014,2018)$, principalmente nos períodos que precedem a sua institucionalização no ensino superior (1930-1940), a proximidade com os militares é descrita como um forte elemento para sua profissionalização e seu reconhecimento como uma ocupação. Porém, a presença das práticas corporais, como conteúdo incorporado ao processo de formação dos sujeitos no período imperial, retrata que elas também estavam, paulatinamente, sendo disseminadas no âmbito civil, desde o início do século XIX, principalmente com a chegada da família real ao Brasil.

O desembarque da família real portuguesa (1808), em razão dos conflitos napoleônicos que assombravam a Europa, subverteu a lógica colonial que impunha barreiras para o desenvolvimento do Brasil. Tendo se tornado sede do Império português, a cidade assistiu a um notável progresso em vários âmbitos, inclusive na sua estrutura urbana e na esfera dos costumes. ... Foi nesse contexto que surgiram as pioneiras iniciativas de ensino de práticas corporais institucionalizadas, em espaços escolares e não escolares, no meio civil e no militar (Melo, 2018, p.2).

As iniciativas eram incipientes, até mesmo porque a vida em capitais de província, munícipios e vilas no Brasil era bem precária, marcada pelas dificuldades de saneamento, pelo trabalho escravo, por um comércio não muito desenvolvido, e por alto índice de analfabetismo e epidemias (Schwarcz, 1998; Gondra, 2008). Os agentes envolvidos com o processo da valorização das práticas corporais institucionalizadas estavam vinculados a grupos de militares, médicos, imigrantes, educadores e políticos que advogavam a favor dos benefícios das atividades físicas para o desenvolvimento do vigor físico, da saúde, da moral e da capacidade intelectual das pessoas, e, comumente, as prescrições e intervenções voltavam-se para a realidade da capital imperial. Da promoção de jogos, exercícios físicos, recreações e competições atléticas, não bastava apenas a prática efetiva de certas habilidades ou performances, mas houve a necessidade de esse grupo emergente demarcar seu território, divulgar seus conhecimentos e propagar os benefícios das suas práticas em diferentes esferas sociais (Souza Neto, 1999, p.49).

As ações para a disseminação cultural das práticas corporais e para a legitimação dos papéis que elas poderiam desempenhar na sociedade brasileira, isso por meio do exercício de um ofício, foram impressas em leis e decretos aprovados para a regulação e definição dos contornos de atuação dos mestres, nas diferentes instituições e para diferentes grupos de interesse. Assim sendo, a categorização dos dados de pesquisa permitiu visualizar a presença das práticas corporais nos três segmentos sociais já informados: escolas civis, sociedades ginásticas e instituições militares. Os dados de cada segmento serão descritos e discutidos a seguir.

\section{A educação física nas instituições educacionais}

Um dos primeiros documentos que menciona a "educação physica" é a Carta Imperial de 30 abril de 1828, que aprova os estatutos da Casa Pia e Colégio de São Joaquim dos Meninos Órfãos da Cidade da Bahia. Nessa carta, recomendava-se que os colegiais se 
exercitassem sob a orientação de um responsável por garantir a organização e os estímulos para as atividades, assim como corrigir sua execução simétrica, como era o costume para a boa educação prevista em plano geral:

$\S 9^{\circ}$ Durante este tempo de exercício, que durará meia hora, ou pouco mais, poderão os colegiais empregar-se em toda a sorte de movimentos próprios a fortificar o corpo, como 'correr, saltar, subir as árvores, lutar, levantar e transportar pesos, jogar a bola ou laranjinha, a pela, o volante, e quaisquer outros jogos desta natureza', sendo lícito desembaraçar-se então da guamaxa, e mesmo dos sapatos, para maior liberdade. 'Ficará ao cuidado do superior' que assistir, 'o dirigir de alguma maneira estes exercícios', fazendo que 'os colegiais se sirvam de ambos os braços para os fortificar com igualdade' (Brasil, 1828; destaques nossos).

Os exercícios para o fortalecimento e a ocupação dos alunos estavam previstos no plano de educação física, que, por sua vez, era corrigido e acompanhado periodicamente pelo professor de medicina e cirurgia, responsável pelo tratamento dos doentes e pela vistoria de todos os itens relativos à economia da saúde dos colegiais no estabelecimento. Os responsáveis por tais atividades ainda não se definiam como mestres de educação física, muito provavelmente, pensando com Tardif (2012), porque a posse e utilização de determinados saberes repousam sobre um sistema que vem garantir sua legitimidade e guiar sua definição e orientação. Então tratava-se de condição ainda muito distante para os ofícios vinculados às práticas corporais no cenário brasileiro oitocentista. Nas áreas teóricas, era comum os responsáveis pelas matérias ser chamados de professores e/ou catedráticos, e os responsáveis pelas matérias práticas ou técnicas, de mestres.

Em geral, os mestres não poderiam participar dos julgamentos dos alunos nas avaliações que aconteciam ao final de cada período letivo. Por serem considerados possuidores de uma cultura acadêmica abrangente, necessária para os exames gerais, apenas professores, diretores e o reitor avaliavam os alunos (Cunha Júnior, 2003). A instrução teórica, fundamentada nos preceitos científicos de arguição, classificação e categorização, era vista como o grande trunfo para a formação intelectual, principalmente, dos filhos das elites, que seriam os "pensadores", não importando a capacidade de "executar" alguma ação. A resistência à técnica é marcante nas iniciativas da formação profissional do século XIX, prevalecendo a cultura literária, sendo a ciência o foro de maior respeitabilidade e distinção social entre os letrados e os não letrados (Barato, 2003). Mesmo assim, é inegável a presença da técnica, mesmo que secundarizada nos currículos educacionais e sem cursos oficiais para a formação dos mestres responsáveis para tais ofícios.

Em 1857, foram aprovados os "regulamentos para os colégios públicos da corte" (Brasil, 1857). Os currículos dos colégios públicos deveriam ser organizados em 7 anos. O aluno formado pelo secundário teria o título de bacharel, que lhe dava o direito de pleitear ingresso nas carreiras superiores como a medicina ou o direito. A ginástica, por ser uma matéria com fim principalmente prático, de execução do exercício, não tinha status determinante na carreira escolar do aluno. Dessa forma, como a própria legislação previa no "Art. 10. Para se obter o grau de Bacharel, e o diploma respectivo, assim como o título do curso especial, não são necessários os estudos do desenho, música, dança, e ginástica, e nem o de italiano" (Brasil, 1857). 
Embora os estudos de ginástica não fossem obrigatórios para obtenção do grau de bacharel secundarista, a cadeira estava presente nas escolas fluminenses desde os anos 1830. Em consulta à imprensa periódica, Melo (2018) identificou no Jornal do Commercio, publicado em 1836, que o Colégio Emulação, sob a direção e propriedade do português José Soares de Azevedo, foi um dos primeiros a divulgar na imprensa a oferta de aulas de dança e, de forma gratuita, exercícios ginásticos e natação. Por sua vez, o Imperial Colégio de Pedro II, fundado em 1837 e conhecido como Colégio da Corte, era a principal referência do ensino escolar para a época, pois tinha o papel de formar os filhos das elites, respeitando as influências da educação europeia que chegavam ao Império. Nele, chama a atenção a oferta dos conteúdos de música, desenho e ginástica. No Pedro II, a ginástica teve o seu primeiro mestre nomeado em 1841, Guilherme Luiz de Taube, que, a partir dos documentos para contratação entregues ao reitor do colégio, atestava a sua vasta experiência com ginástica no Exército imperial (Cunha Júnior, 2008).

A presença e a valorização da ginástica indicavam tempos de mudanças dos costumes e fortes embates no contexto institucional, sobre o que deveria constituir a educação da elite imperial. Por mais que a educação técnica fosse sobrepujada pela educação literária, composta pelas artes e ciências, é importante situar que a valorização ou não da experiência prática estava relacionada à estrutura econômica, social e cultural. A repressão e a exclusão social limitavam o ensino na escola às elites imperiais, levando o trabalho a ser priorizado nas classes sociais desfavorecidas (Villalta, 1997). O mestre era o possuidor do saber técnico, próprio para o trabalho. O saber técnico tinha como característica a ausência da orientação geral e de significado humano, os quais eram atributos das disciplinas literárias (Barato, 2003).

Na segunda metade do século XIX, a sociedade brasileira vivia transformações estruturais, como o mercado de trabalho livre (Gebara, 1986), a rediscussão do papel do Estado-nação e a emergência do Partido Republicano. Por sua vez, a educação passou a receber cada vez mais atenção nos debates. Para Bastos (2006), a educação encontrava-se em período profícuo de debates nos eventos promovidos (congressos, exposições, seminários) e nas reformas propostas como preceitos gerais.

Em 1879, com a "Reforma do ensino primário e secundário no município da Côrte e o ensino superior em todo Império", fica registrada a publicação de diretrizes para as escolas de ensino primário, tanto de cunho privado - que eram a maioria - quanto público, assim como os cursos de formação superior (Brasil, 1879). Nesse momento, a ginástica passa a ser considerada obrigatória nas escolas primárias e secundárias, condição a ser reiterada em 1882 pela "Reforma do ensino primário e várias instituições complementares da instrução pública”, a qual teve como principal relator Rui Barbosa, que, segundo Moreno (2003), sugere a inclusão da ginástica sueca nas escolas por ser de forte caráter pedagógico. Assim, seguindo experiências europeias, as instituições deveriam passar a selecionar os professores por concurso, enquanto os mestres de ginástica, música e desenho continuavam a ser selecionados por nomeação e portarias.

Os mestres já atuantes nas escolas normais ${ }^{3}$ recebiam $600 \$ 000$ (contos de réis) de ordenado e mais $400 \$ 000$ de gratificação, totalizando $1.000 \$ 000$ anuais. Após a publicação do decreto (Brasil, 1879), os mestres teriam um aumento para $800 \$ 000$ de ordenado e mais $400 \$ 000$ de gratificação, totalizando $1.200 \$ 000$ anuais, metade do que recebia um 
professor substituto. Os professores concursados teriam um ordenado de $1.600 \$ 000$ e mais $800 \$ 000$ de gratificação no primeiro ano, além do aumento para $2.400 \$ 000$ e mais gratificação de $1.200 \$ 000$ no segundo ano, totalizando $3.600 \$ 000$ anuais. A questão da remuneração e da carga de trabalho destinada aos mestres foi uma situação delicada nos estabelecimentos de ensino.

Por um lado, ainda que de forma tímida, a ginástica passara a ser introduzida e valorizada como conteúdo para a educação da sociedade em transformação. Segundo Herold Júnior (2007), ela ocupara centralidade nos debates registrados em atas e pareceres do Congresso de Instrução do Rio de Janeiro em 1884, quando muitos a defendiam para o contexto escolar conectada aos movimentos pedagógicos, à racionalidade e à cientificidade, para então adjetivá-la de educativa, para que ela deixasse de ser encarada como um mero exercício desenvolvedor de músculos e obliterador da moral, do intelecto e da saúde. Mas, por outro lado, a natureza prática dos conteúdos imputava aos mestres desse ofício um status inferior perante a legislação educacional. Essas condições podem ter servido de barreiras para um real investimento em cursos de formação de mestres e professores de educação física e nas diversas áreas das práticas corporais para disseminação da cultura da educação do corpo de forma mais abrangente na sociedade em escolarização.

\section{A educação física nas escolas militares}

No século XIX houve a emergência do grupo militar em nome da constituição do exército do Estado-nação, sendo fortalecido o seu espírito corporativo de classe armada na segunda metade do período. O grupo militar ampliou força e espaço na sociedade civil, inclusive nas escolas, onde, conforme Goellner (1992), a educação física figurou como sua aliada, sendo os métodos de ginástica um mecanismo de fortalecimento do poderio militar.

Nas escolas militares, o ensino era dividido entre comum e auxiliar. O ensino comum seria composto por disciplinas ditas teóricas, como física e retórica. Por outro lado, o ensino auxiliar era composto por disciplinas práticas, que ressaltavam o lado técnico dos conteúdos da escola militar. A instrução prática era definida como treinamento para as ações de guerra. As diferentes "armas" do Exército eram a ginástica, a esgrima e a natação. O treinamento nessas três modalidades capacitaria o indivíduo para as ações de guerra. O ensino teórico ficaria a cargo das disciplinas de aritmética, álgebra, geometria, desenho linear, administração de companhia, história, língua francesa, língua inglesa e gramática portuguesa (Brasil, 1874). Todos os alunos que passassem pelas escolas preparatórias estariam aptos a "Art. 35. ... adquirir os conhecimentos especiais às três armas do exército e aos corpos de estado maior da $1^{a}$ classe e de engenheiros" (Brasil, 1874). É importante ressaltar que os oficiais e engenheiros formados pelas escolas militares posteriormente ocupariam cargos de práticas de ginástica, natação e esgrima nas escolas civis.

A partir dos anos 1860 a ginástica nos estabelecimentos militares tinha como principal referência o método alemão (Marinho, s.d.; Soares, 1994). Alguns de seus mestres foram oficiais alemães reformados e adeptos do documento conhecido como Novo guia para o ensino de ginástica nas escolas da Prússia, que, traduzido, configurou um manual de ginástica divulgado por ordem expressa do ministro do Império (Goellner, 1992). ${ }^{4}$ Nesse cenário, a 
ginástica propagava-se nas escolas militares e no Exército, embora com ausência de padrão e infraestrutura suficiente, figurava como uma forma sistematizada de trabalho de um ofício em construção.

Nas províncias em desenvolvimento, as escolas militares foram se instalando e organizando o quadro de funcionários e oficiais com o objetivo de absorver e formar a juventude brasileira para o Exército. Os mestres de ginástica, natação e esgrima faziam parte das companhias, juntamente com farmacêuticos, médicos, engenheiros, capelães e professores de primeiras letras e seus adjuntos. Dessa forma, a ginástica, entre outros serviços escassos para a população das províncias, era disseminada no interior do Império.

Convenientemente, o Estado recolhia, alfabetizava e preparava os jovens soldados para o manejo das armas, oferecendo a ginástica como forma de fortalecer os meninos à altura do tipo de artefato que deveriam carregar (Ferreira Neto, 1999). Dessa forma, as práticas corporais no contexto militar desempenhavam um papel diferente daquele que vimos no contexto das instituições civis: o papel de legitimar as atribuições e qualidades dos soldados formados pelas escolas militares em nome da suposta defesa nacional do Estado brasileiro. Apesar das matérias ditas científicas nos cursos de formação, a presença dos exercícios sistematizados garantiria a disciplina e a ordem da massa de aprendizes que se alistavam nas companhias.

Em 1886, o governo inicia o processo de centralização de algumas escolas militares. A Escola da Marinha e o Colégio Naval passam a denominar-se Escola Naval, reunindo em um só lugar o curso preparatório, o de náutica e o curso superior (Brasil, 1886). O curso preparatório, composto por 3 anos de estudos, serviria de base aos outros, nesse momento integrados na mesma escola. A idade admitida para o preparatório era de 12 anos. As matérias de desenho figurado e de paisagem, ginástica, natação e infantaria faziam parte do programa do curso preparatório à carreira militar. "As habilitações em esgrima, natação, tecnologia marítima, infantaria, ginástica e prática-técnica serão conferidas pelas médias dos coeficientes de merecimento obtidos durante o ano" (Brasil, 1886). O coeficiente era a média dos valores obtidos em cada matéria, considerando todo o processo ao longo do ano de estudo. Caso fossem reprovados nas avaliações, os estudantes poderiam repetir o ano. Como reflexo, os mestres de esgrima, ginástica e natação, no ano de 1887, passam a usufruir das mesmas vantagens dos oficiais de estado-maior de segunda classe, com benefícios como gratificações e descansos, algo até então previsto apenas para os oficiais das matérias teóricas. Para a formação superior militar, o mestre de esgrima e ginástica, nessa lei, passa a receber $720 \$ 000+720 \$ 000=1.440 \$ 000$, valor que representa uma conquista a um grupo profissional emergente naquele momento.

A educação verticalizada, altamente controlada pelo repertório técnico e científico, e delimitada apenas aos membros das corporações militares, de acordo com Freidson (1998), fomentava o status de exclusividade e o sentimento de privilégio daqueles que faziam parte desse meio. Tal cenário era favorável para alimentar a profissionalização de ofícios ligados às práticas corporais nas instituições militares de forma mais contundente em comparação às instituições civis, muito provavelmente, pelo papel essencial que as práticas corporais exerciam na educação militar e com sua inserção na sociedade civil. 


\section{A educação física nas sociedades ginásticas}

Além da presença da ginástica na educação civil e militar, retratada na legislação imperial, é possível observar que, fora das escolas, a ginástica, as lutas, a dança, entre outras formas de práticas corporais existentes em outros países, já eram disseminados por meio das sociedades ginásticas que se instalavam no Brasil. Em geral, essas sociedades se distinguiam pela referência ao país de origem dos fundadores, tais como: Sociedade Alemã de Ginástica, Congresso Ginástico Português, Sociedade Francesa de Ginástica, Club de Regatas Guanabarense. Todos esses clubes foram identificados na legislação do Império entre os anos de 1860 e 1870.

As sociedades alemãs tiveram grande peso na disseminação da cultura germânica, principalmente no sul do Brasil, onde o maior número de colonos se instalou e fundou clubes teuto-brasileiros (Tesche, 1996; Quitzau, 2016). Segundo Jesus (2001, p.2), "no censo de 1872, os alemães figuram como o terceiro grupo estrangeiro mais numeroso no Brasil, ficando atrás somente de portugueses e 'africanos' (estes tomados assim indistintamente)". Como evidencia Quitzau (2016), já no terceiro quartel do século XIX, duas sociedades ginásticas alemãs foram fundadas no sul do Brasil, a Deutscher Turnverein Porto Alegre, em 1867, que viria a constituir a Turnerbund Porto Alegre em 1892 e a Turnverein Blumenau em 1873. A sociedade fundada em 1867 perdura até nossos dias, com o nome de Sociedade Ginástica Porto-alegrense (Sogipa).

Os princípios atléticos alemães eram balizados pelo nível físico (material ou espacial), com a criação de objetos e equipamentos destinados à prática e à apropriação de espaços ao ar livre, como praças, parques e outras áreas para tal finalidade. Segundo o estatuto da Sociedade Alemã de Ginástica, aprovado pelo decreto n.2.980, de 4 de outubro de 1862, os sócios dos clubes votavam e nomeavam os próprios membros para a composição da Junta dos Ensaiadores dos Exercícios, os quais tinham a responsabilidade de "dirigir os exercícios", "dividir os exercitantes em diferentes turmas" e "cuidar na aquisição de novos aparelhos" (Brasil, 1862). Dessa forma, o ensino e a prática das modalidades comuns para a época ficavam a cargo dos próprios membros, como forma de garantir a reprodução das matrizes culturais vindas ao Brasil com a imigração.

Por sua vez, a Sociedade Francesa de Ginástica, autorizada a funcionar pelo decreto n.4.700, de 21 de fevereiro de 1871, introduzia no Brasil a ginástica científica, difundida inicialmente por Francisco Amoros y Ondeaño no continente europeu no final do século XVIII e início do XIX. O método gímnico de Amoros, integrando ideais franceses liberais de que todo cidadão tem direitos para se desenvolver como "homem universal", voltava-se a valores patrióticos, morais, higiênicos, estéticos e sociais com finalidades civil e industrial, militar, educativa, médica e cênica ou funambulesca (Soares, 1994). ${ }^{5}$

Dessa forma, as atividades na Sociedade Francesa de Ginástica deveriam ser organizadas em três cursos: ginástica, música e esgrima. A principal função da sociedade era descrita da seguinte forma: "Ela tem por fim: $1^{\circ}$ dar a seus membros a faculdade do estudo da ginástica e o estudo suplementar da esgrima e da música, fornecendo-lhes os professores necessários" (Brasil, 1871). "Cada professor que estivesse à frente de um dos cursos da 
sociedade seria o responsável por organizar as lições e o cronograma como bem entender" (Brasil, 1871), contanto que estivesse de acordo com as orientações da diretoria. Cada professor iria receber os honorários de $50 \$ 000$ mensais, que viriam das mensalidades dos sócios do clube. Os responsáveis por ginástica, esgrima ou música não tinham nessas atividades a principal fonte do seu sustento, já que a permanência como membro em uma sociedade demandava altos investimentos com inscrição, mensalidades, compra de vestuários próprios para cada atividade e para datas especiais, entre outras contribuições compulsórias.

Com objetivos mais direcionados às atividades recreativas, a sociedade denominada Congresso Ginástico Português, aprovada pelo decreto n.5.873, de 13 de fevereiro de 1875, "tem por fim proporcionar aos seus sócios recreios honestos e agradáveis" (Brasil, 1875). Nessa perspectiva, além dos cursos de ginástica, esgrima e música, a sociedade oferecia encontros diários com "entretenimentos inocentes" e "passeios campestres", típicas práticas das famílias da corte portuguesa. A afeição do imperador pela sociedade portuguesa de ginástica rapidamente ganhou prestígio entre os clubes sociais da época. Tanto que, em 1876, o rei manda alterar o nome da sociedade para Real Sociedade Clube Ginástico Português. Sustentando o status de clube do rei, a sociedade portuguesa tinha como política nomear sócios honorários, os quais eram "pessoas notáveis em literatura, música, esgrima ou ginástica, que tenham prestado serviços à Sociedade"(Brasil, 1875).

Como registro de experiência, o Congresso Ginástico Português (em 1878) e a Sociedade Francesa de Ginástica (em 1863) contaram com as contribuições do trabalho dos mestres Paulo Vidal e Vicente Casali, para concretização de uma ginástica que trazia para cena uma prática corporal festiva e desafiadora, mas também controlada e racionalizada, visando a exibições pautadas na execução de difíceis exercícios em barra fixa e horizontal, trapézio, argolas, trampolim e outros aparelhos (Romão, Moreno, 2018). Em sociedades e clubes de ginástica, praticavam exercícios gímnicos e assistiam a "espetáculos do corpo", que, para tanto, careciam de agentes na promoção.

Interessante observar que as sociedades ginásticas, apesar de atender às elites imperiais, nutriam certa autonomia para a elaboração e o controle dos métodos de ensino e treinamento das atividades corporais. Organizavam-se independentemente de outras instituições sociais. Para os sócios, eram locais exclusivos na alta sociedade para vivenciar as práticas pela relativa liberdade de escolha. Ser membro de uma sociedade ginástica era uma decisão individual, pois o papel dessas práticas era recreativo, contemplativo e social. Podemos considerar que as sociedades fomentavam um processo de socialização de um universo simbólico existente em outros países, implicando aquilo que Berger e Luckmann (1997) denominaram uma rudimentar institucionalização de práticas comuns de uma sociedade aplicada à outra, e que na realidade brasileira passara por apropriações culturais. A transição de métodos e conteúdos subjacentes socializados na cultura nacional, pela dimensão da educação do corpo, contribuiu para a popularização e construção de uma identidade coletiva daqueles que atuavam com as práticas corporais no período imperial brasileiro. 


\section{A profissionalização da educação física}

O sentimento de pertencimento e de autoidentificação com o trabalho são fatores fundamentais para a construção de uma ocupação. Contudo, para a institucionalização da profissão, a socialização profissional precisa acontecer por meio das instituições educativas, geralmente de formação superior, que permitem instaurar uma formação específica (Freidson, 2001). O retrato dos profissionais das práticas corporais no presente estudo revela que a formação ainda não era o imperativo definidor das suas carreiras. Não exerciam o ofício de mestre de forma integral, não existiam escolas de treinamento para sua formação específica e muito menos associações de classe, como já acontecia nos casos da enfermagem, da medicina ou dos professores das cadeiras teóricas. As tarefas profissionais dos mestres de ofícios ainda representavam ações desarticuladas, com pouca mobilização coletiva dos sujeitos envolvidos com as práticas corporais. E, como Freidson (2001) explica, os membros de uma ocupação precisam acreditar que as tarefas que desempenham são exclusivas, de forma que aqueles que compartilham a mesma atividade sintam-se parte de uma comunidade de trabalho.

Naturalmente, o ideal de profissão (Bosi, 1996) ainda não era um elemento concreto nas rudimentares articulações dos mestres vinculados aos ofícios das práticas corporais. Mesmo assim, para fazer parte do corpo de mestres de escola, clube ou sociedade recreativa, a vasta experiência com a ginástica, a natação ou com a esgrima já era um pré-requisito. Das exigências atribuídas aos mestres, a experiência prática foi o primeiro elemento característico da profissão para delimitar o acesso daqueles que não tinham o mesmo reportório de saberes (Freidson, 1998).

Fora a experiência prática, não havia ainda estratégias exclusivas para assegurar a autoridade profissional, tornando as práticas corporais ofícios desarticulados profissionalmente. Por um lado, havia o senso comum da existência na hierarquia da teoria sobre a prática. Portanto, dos professores "intelectuais" com relação aos mestres "práticos". Por outro lado, um conjunto de fatores, como remuneração, dedicação e baixo status social eram os maiores desafios para o desenvolvimento das práticas corporais como área ocupacional minimamente organizada. Haveria a necessidade de agregar valor aos saberes, produzindo conhecimentos sobre os exercícios ou novos significados às práticas corporais, relevantes para a sociedade e, assim, ampliar o grau de identificação e dedicação às tarefas da ocupação. Essa seria uma forma de exercer o controle sobre o próprio trabalho (Aldridge, Evetts, 2003), ideal para o profissionalismo (Freidson, 2001).

É nesse sentido que, aos poucos, a importância dos papéis sociais que as práticas corporais demarcaram na sociedade brasileira, em um período intenso de transição cultural e identitária, precisa ser realçada. Os mestres figuraram como os protagonistas desse cenário. As mesmas atividades laborais desempenharam objetivos distintos em cada contexto. Podemos citar o papel educativo-higiênico das práticas corporais nas escolas e institutos, o papel disciplinar no contexto militar e os fins recreativos nos clubes e sociedades. Cada espaço social teve o seu peso para a construção coletiva de uma cultura ocupacional. Sendo assim, mesmo que para fins distintos, diferentes habilidades e tarefas foram executadase conectadas por algum tipo de conhecimento especializado. 
A diferenciação entre os profissionais pelo critério da experiência, por exemplo, expõe a regulação da prática como resultado da luta por autoridade social e cultural ${ }^{6}$ do trabalho (Starr, 2017; Abbott, 1988). Tal autoridade não reside apenas na competência e perícia em si, mas na capacidade de o profissional oferecer influência política, prestígio e aumentar o grau de governabilidade, o que era interessante para o Estado (Coelho, 1999), a exemplo da presença das práticas corporais nas instituições educacionais.

Abbot (1988) cunhou a ideia de que as profissões disputam por jurisdições e competem pela propriedade dos problemas e pela responsabilidade em sua solução. Em se tratando de problemas públicos, tais como criminalidade, alcoolismo, prostituição e saúde pública, a competição entre as ocupações que seriam responsáveis pelo domínio dos problemas (capacidade de definir sua natureza e formular teorias sobre sua causalidade), e a responsabilidade pela solução, é resolvida pela formulação de políticas públicas pelo Estado (Coelho, 1999). Quem legisla sobre a essência dos problemas domina, pelo menos culturalmente, a competição sobre aqueles que serão reconhecidos por um status especial e pela confiança na condução de certas atividades (Coelho, 1999). Sendo assim, as fontes de regulamentações oficiais refletem as marcas que se institucionalizaram e repercutiram nas responsabilidades das práticas corporais em processo de profissionalização. Edifica-se, dessa forma, uma estrutura ocupacional interdependente com a sociedade. Paulatinamente, mais do que uma estrutura ocupacional, desenvolvem-se os primeiros passos de uma socialização da profissão que, no século XX, ficou conhecida nacionalmente como educação física.

\section{Considerações finais}

Neste artigo foram analisadas e discutidas as germinais articulações profissionais vinculadas às práticas corporais registradas na legislação imperial, pelo ponto de vista teórico-conceitual da sociologia das profissões. Após a análise dos documentos imperiais foi possível afirmar que existiam grupos interessados nas práticas corporais (educadores, militares, imigrantes) e no poder mobilizador que tais práticas alcançavam nos diferentes grupos sociais.

No entanto, uma das questões que este trabalho trouxe para nossa reflexão foi: as características dos ofícios e as ações dos mestres vinculados às práticas corporais poderiam ser considerados um rudimentar processo de profissionalização da ocupação "educação física" no Brasil?

Acreditamos que essas premissas podem ser consideradas pelas seguintes argumentações:

(a) Há no período imperial grupos interessados nas práticas corporais como componente educativo, tanto nas instituições escolares quanto nas instituições para a formação militar e culturais;

(b) A instrução das práticas era destinada aos que já apresentavam algum tipo de domínio sobre as tarefas de cada modalidade e eram reconhecidos por tais conhecimentos, favorecendo a socialização de conhecimentos e métodos que destacavam a existência rudimentar de um grupo profissional, mesmo que ainda pouco valorizado em comparação com os professores das matérias teóricas; 
(c) Apesar da baixa autonomia nas instituições escolares, no campo extraescolar a gestão das atividades era desempenhada pelos próprios mestres e membros das sociedades, favorecendo a construção da noção de exclusividade de certas práticas corporais, o que é um elemento fundamental para cunhar a autoridade cultural de uma profissão;

(d) Para fazer parte das diferentes instituições de formação na sociedade brasileira, os mestres entusiastas da natação, ginástica, esgrima, equitação, entre outras práticas corporais, se articularam de alguma forma para reivindicar equidade de direitos funcionais, compartilhar saberes e adaptar métodos a diferentes realidades. Portanto, foi construída uma base favorável para que as práticas corporais se tornassem uma questão de interesse coletivo.

Sabe-se que a legislação do Império procede em grande parte de regulamentos copiados de instituições inglesas, americanas e francesas, nas quais as práticas corporais vieram a reboque dos modelos existentes em outros países (Coelho, 1999). Portanto, temos claro que a institucionalização das práticas corporais na legislação do Império aconteceu pari passu com a profissionalização do próprio Estado brasileiro.

Por fim, a sociogênese e as condições para a articulação dos profissionais interessados na área e para a profissionalização da educação física como categoria organizada ainda constituem tema pouco discutido pela comunidade acadêmica. Portanto, torna-se necessário que mais estudos abordem as condições para a profissionalização da educação física nos diferentes momentos históricos, para uma leitura contextualizada sobre o processo da carreira e da identidade profissional na constituição de uma sociologia da profissão na área.

\section{AGRADECIMENTO}

Os autores agradecem o apoio da Fundação de Amparo à Pesquisa do Estado de São Paulo (Fapesp).

\section{NOTAS}

${ }^{1}$ Para mais informações sobre Guilherme Luiz de Taube e o ensino de ginástica no Colégio Pedro II, ver Cunha Júnior (2008).

${ }^{2}$ As leis e os decretos são normas legais que servem para regular as ações e condutas sociais. A lei é um instrumento que autoriza a legislação das questões específicas relativas aos assuntos das leis, enquanto os decretos são os atos normativos, relacionados às ações desencadeadas por alguma lei (Bittencourt, Clementino, 2012).

${ }^{3}$ A primeira escola normal brasileira, para formação de professores, foi fundada em 1835, em Niterói (RJ). Sobre as escolas normais no Brasil, ver Araújo, Freitas e Lopes (2008).

${ }^{4} \mathrm{O}$ método alemão perderá a sua hegemonia no contexto militar com a introdução do método francês na primeira década do século XX, ver Marinho (s.d.), Castellani Filho (1988), Goellner (1992) e Soares (1994).

${ }^{5}$ No Brasil, a ginástica francesa se espraiará na sociedade com maior força no início do século XX. Ver Goellner (1992) e Soares (1994, 2005).

${ }^{6}$ A autoridade social envolve o controle das ações por meio de comandos explícitos. A autoridade cultural, por sua vez, implica a construção da realidade por meio de fatos e valores, assim como reside em objetos culturais, tais como são os livros para os intelectuais e a bíblia para o religioso (Starr, 2017). 


\section{REFERÊNCIAS}

ABBOTT, Andrew. The system of professions. Chicago: University of Chicago Press, 1988.

ALDRIDGE, Meryl; EVETTS, Julia. Rethinking the concept of professionalism: the case of journalism. British Journal of Sociology, v.4, n.54, p.547-564, 2003.

ANDRADE FILHO, Nelson Figueiredo de. Currículo e conhecimento para a formação profissional em educação física brasileira. In: Congresso Brasileiro de Ciências do Esporte, 12., 2001, Caxambu. Anais..., v.12. Caxambu: Direção Nacional/Colégio Brasileiro de Ciências do Esporte; Secretaria Estadual de Esportes de São Paulo; Secretaria Estadual de Esporte de Minas Gerais, 2001. p.1-10.

ARAÚJO, José Carlos Souza; FREITAS, Anamaria Gonçalves Bueno de; LOPES, Antônio de Pádua Carvalho. As escolas normais no Brasil: do Império à República. Campinas: Alínea, 2008.

BARATO, Jarbas N. A técnica como saber: investigação sobre o conteúdo do conhecimento do fazer. Tese (Doutorado em Educação) Universidade Estadual de Campinas, Campinas, 2003.

BASTOS, Maria H.C. A educação como espetáculo. In: Bastos, Maria H.C.; Stephanou, Maria (org.). Histórias e memórias da educação no Brasil. Petrópolis: Vozes, 2006.

BERGER, Peter L.; LUCKMANN, Thomas. $A$ construção social da realidade. Petrópolis: Vozes, 1997.

BITTENCOURT, Priscila de O.S.; CLEMENTINO, José C. Hierarquia das leis. Revista Alumni, v.2, p.6, 2012.

BOSI, Maria L.M. Profissionalização e conhecimento: a nutrição em questão. São Paulo: Hucitec, 1996.

BRANTE, Thomas. Professions as science-based occupations.Professions and professionalism, v.1, n.1, p.4-20, 2011. Disponível em: https:// journals.hioa.no/index.php/pp/article/ view/147/143. Acesso em: 22 abr. 2017.

BRASIL. Decreto n.9.611, de 26 de junho de 1886. Reúne em um só estabelecimento, sob a denominação de Escola Naval, a Escola de Marinha e o Colégio Naval. In: Brasil. Coleção das leis do Império do Brasil. Rio de Janeiro: Imprensa Nacional, 1886. Disponível em: http://www2. camara.leg.br/atividade-legislativa/legislacao/ publicacoes/doimperio. Acesso em: 23 mar. 2018.

BRASIL. Decreto n.7.247, de 19 de abril de 1879. Reforma o ensino primário e secundário no município da Côrte e o superior em todo o Império. In: Brasil. Coleção das leis do Império do Brasil. Rio de Janeiro: Imprensa Nacional, 1879. Disponível em: http://www2.camara.leg. br/atividade-legislativa/legislacao/publicacoes/ doimperio. Acesso em: 23 mar. 2018.

BRASIL. Decreto n.5.873, de 13 de fevereiro de 1875. Aprova os estatutos da sociedade denominada Congresso Ginástico Português. In: Brasil. Coleção das leis do Império do Brasil. Rio de Janeiro: Imprensa Nacional, 1875. Disponível em: http://www2.camara.leg.br/atividadelegislativa/legislacao/publicacoes/doimperio. Acesso em: 10 ago. 2014.

BRASIL. Decreto n.5.529, de 17 de janeiro de 1874. Aprova o regulamento para as escolas do exército. In: Brasil. Coleção das leis do Império do Brasil. Rio de Janeiro: Imprensa Nacional, 1874. Disponível em: http://www2.camara.leg. br/atividade-legislativa/legislacao/publicacoes/ doimperio. Acesso em: 10 ago. 2014.

BRASIL. Decreto n.4.700, de 21 de fevereiro de 1871. Concede à Sociedade Francesa de Ginástica autorização para continuar a funcionar, e aprova os seus estatutos. In: Brasil. Coleção das leis do Império do Brasil. Rio de Janeiro: Imprensa Nacional, 1871. Disponível em: http://www2.camara.leg.br/atividadelegislativa/legislacao/publicacoes/doimperio. Acesso em: 10 ago. 2014.

BRASIL. Decreto n.2.980, de 4 de outubro de 1862. Concede à Sociedade Alemã de Ginástica autorização para continuar a exercer as suas funções, e aprova os respectivos Estatutos. In: Brasil. Coleção das leis do Império do Brasil. Rio de Janeiro: Imprensa Nacional, 1862. Disponível em: http://www2.camara.leg.br/atividadelegislativa/legislacao/publicacoes/doimperio. Acesso em: 10 ago. 2014.

BRASIL. Decreto n.2.006, de 24 de outubro de 1857. Aprova o regulamento para os colégios públicos de instrução secundária do Município da Corte. In: Brasil. Coleção das leis do Império do Brasil. Rio de Janeiro: Imprensa Nacional, 1857. Disponível em: http://www2.camara.leg. br/atividade-legislativa/legislacao/publicacoes/ doimperio. Acesso em: 10 ago. 2014.

BRASIL. Carta Imperial de 30 de abril de 1828. Aprova os estatutos da Casa Pia e Colégio de S. Joaquim dos Meninos Órfãos da cidade da Bahia. In: Brasil. Coleção das leis do Império do Brasil. Rio de Janeiro: Imprensa Nacional, 1828. Disponível em: http://www2.camara.leg.br/ atividade-legislativa/legislacao/publicacoes/ doimperio. Acesso em: 10 ago. 2014. 
CASTELLANI FILHO, Lino. A educação física no Brasil: a história que não se conta. Campinas: Papirus, 1988.

COELHO, Edmundo Campos. As profissões imperiais: medicina, engenharia e advocacia no Rio de Janeiro, 1822-1930. Rio de Janeiro: Record, 1999.

CUNHA JÚNIOR, Carlos Fernando Ferreira. Imperial Colégio de Pedro II: o ensino secundário da boa sociedade brasileira. Rio de Janeiro: Apicuri, 2008.

CUNHA JÚNIOR, Carlos Fernando Ferreira. Os exercícios ginásticos no Imperial Colégio de Pedro Segundo, 1841-1870. Revista Brasileira de Ciências do Esporte, v.25, n.1, p.69-81, 2003.

FARIA FILHO, Luciano Mendes. A legislação escolar como fonte para a história da educação: uma tentativa de interpretação In: Duarte, Regina Horta; Faria Filho, Luciano Mendes de (org.). Educação, modernidade e civilização: fontes e perspectivas de análises para a história da educação oitocentista. Belo Horizonte: Autêntica, 1998. p.89-125.

FERREIRA NETO, Amarílio. A pedagogia no exército e na escola: a educação física brasileira, 1880-1950. Aracruz: Facha, 1999.

FREIDSON, Eliot. Professionalism, the third logic: on the practice of knowledge. Chicago: Universityof Chicago Press, 2001.

FREIDSON, Eliot. Renascimento do profissionalismo. São Paulo: Edusp, 1998.

GEBARA, Ademir. O mercado de trabalho livre no Brasil, 1871-1888. São Paulo: Brasiliense, 1986.

GERMINIANI, Clotilde de L.B. A história da medicina veterinária no Brasil. Archives of Veterinary Science, n.3, v.1, p.1-8, 1998.

GOELLNER, Silvana Vilodre. O método francês e a educação física no Brasil: da caserna à escola. Dissertação (Mestrado em Ciência do Movimento Humano) - Universidade Federal do Rio Grande do Sul, Porto Alegre, 1992.

GONDRA, José G. Educação, poder e sociedade no Império brasileiro. São Paulo: Cortez, 2008.

HEROLD JÚNIOR, Carlos. A educação física nas atas do Congresso de Instrução do Rio de Janeiro, 1884. Revista HISTEDBR, n.26, p.114129, 2007.

JESUS, Gilmar M. de. Imigrantes desportistas: os alemães no sul do Brasil. Revista Electrónica de Geografía y Ciencias Sociales, n.94, v.108, 2001. Disponível em: http://www.ub.edu/geocrit/sn94-108.htm. Acesso em: 24 mar. 2021.
MARINHO, Inezil P. História da educação física no Brasil. São Paulo: Companhia Brasil Editora, s.d.

MELO, Victor Andrade de. Preocupações com a educação física: o ensino de práticas corporais nas escolas fluminenses (1836-anos 1850). Educação e Pesquisa, v.44, e175905, p.1-28, 2018.

MELO, Victor Andrade de. Experiências de ensino da dança em cenários não escolares no Rio de Janeiro do século XIX (décadas de 18201850). Movimento, v.22, n.2, p.497-508, 2016.

MELO, Victor Andrade de; PERES, Fabio de Farias. O corpo da nação: posicionamentos governamentais sobre a educação física no Brasil. História, Ciências, Saúde - Manguinhos, v.21, n.4, p.1131-1149, 2014.

MORENO, Andrea. O Rio de Janeiro e o corpo do homem fluminense: o 'não lugar' da ginástica sueca. Revista Brasileira de Ciências do Esporte, v.25, n.1, p.55-68, 2003.

PHILLIPS, Bernard S. Pesquisa social. Rio de Janeiro: Agir, 1974.

QUITZAU, Evelise Angarten. Associativismo ginástico e imigração alemã no Sul e Sudeste do Brasil, 1858-1938. Tese (Doutorado em Educação) - Universidade Estadual de Campinas, Campinas, 2016.

RIBEIRO, Márcia M. A ciência dos trópicos: a arte médica no Brasil do século XVIII. São Paulo: Hucitec, 1997.

RODRIGUES, Maria de L. Sociologia das profissões. Oeiras: Celta, 2002.

ROMÃO, Anna Luiza Ferreira; MORENO, Andrea. Das piruetas aos saltos: as diferentes manifestações da 'gymnastica' no Rio de Janeiro da segunda metade do XIX. Cadernos Cedes, v.38, n.104, p.21-32, 2018.

ROSAS, Paulo. Vocação e profissão. Petrópolis: Vozes, 1980.

RUGIU, Antônio S. Nostalgia do mestre artesão. Campinas: Autores Associados, 1998.

SCHNEIDER, Omar. Educação 'physica': a arqueologia de um impresso. Vitória: Edufes, 2010.

SCHWARCZ, Lilia Moritz. As barbas do imperador. São Paulo: Companhia das Letras, 1998.

SOARES, Carmem Lúcia. Imagens da educação no corpo. Campinas: Autores Associados, 2005.

SOARES, Carmem Lúcia. Educação física: raízes europeias e Brasil. Campinas: Autores Associados, 1994.

SOUZA NETO, Samuel. A educação física na universidade: licenciatura e bacharelado: as 
propostas de formação profissional e suas implicações teórico-práticas. Tese (Doutorado em Educação) Universidade de São Paulo, São Paulo, 1999.

STARR, Paul. The social transformation of American medicine. New York: Basic Books, 2017.

STRUNA, Nancy L. Pesquisa histórica em atividade física. In: Thomas, Jerry R. Métodos de pesquisa em atividade física. Porto Alegre: Artmed, 2002. p.228-240.

TARDIF, Maurice. Saberes docentes e formação profissional. Petrópolis: Vozes, 2012.
TESCHE, Leomar. A prática do 'turnen' entre imigrantes alemães e seus descendentes, no Rio Grande do Sul: 1867-1942. Ijuí: Unijuí, 1996.

VILLALTA, Luiz Carlos. O que se fala e o que se lê: língua, instrução e leitura. In: Novais, Fernando A. (coord. geral da coleção); Souza, Laura de Mello e (org. do volume). História da vida privada no Brasil, v.1: cotidiano e vida privada na América portuguesa. São Paulo: Companhia das Letras, 1997. p.332-385. 